RESEARCH ARTICLE

\title{
Knowledge, Attitude and Pattern of Antibiotic Usage among Students of a Nigerian University
}

\author{
Olayemi O. Ayepola, Olabode A. Onile-Ere, Oluwatobi E. Shodeko, Fiyinfoluwa A. Akinsiku, Percy E. Ani, \\ Louis O. Egwari \\ Department of Biological Sciences, Covenant University, Ogun State, Nigeria
}

\begin{abstract}
Objective: Antibiotic resistance is a major public health issue globally fueled largely by its misuse. Controlling this problem would require an understanding of the levels of awareness of the population towards antibiotics.

This study assessed the baseline information on the knowledge, attitude and practice towards antibiotics among university students in Ogun State Nigeria.

Methodology: A cross-sectional study was conducted between January and March 2016 among a convenience sample of undergraduate students attending Covenant University, Ogun State, Nigeria. Self-administered questionnaires were employed to obtain information on knowledge, attitude and practice towards antibiotic usage.

Results: A total of 357 students were recruited into this study. $60.6 \%$ of the participants had taken antibiotics in the 6 months preceding the study of which two-thirds stated that they seldom complete the antibiotic dosage. Doctors $(53.1 \%)$ and parents $(22.9 \%)$ were responsible for most antibiotic prescriptions in this study. Knowledge assessment showed fair knowledge of antibiotic use and drug resistance.
\end{abstract}

Conclusions: This study shows that the study population has average knowledge of antibiotics use hence the need to generate more awareness. J Microbiol Infect Dis 2019; 9(1): 10-15.

Keywords: Antibiotic usage, antibiotic resistance, drug resistance

\section{INTRODUCTION}

Antibiotics are instrumental in reducing the burden of infectious diseases and have become essential for many medical interventions. The emergence of drug resistant pathogens however, is a major threat to public health especially in developing nations. The emergence of drug resistant strains has led to the adoption of more expensive drug variants [1] not easily accessible by persons in low and middle-income nations hence an increase in morbidity and mortality resulting from resistant strains. A major driver of antibiotic resistance is the selection pressure that results from the inappropriate consumption of antibiotics. This is partly influenced by the availability of cheap antibiotics over the counter and the inappropriate prescription of antibiotics by health care personnel $[2,3]$. Controlling this problem would require regulatory measures alongside awareness campaigns to ensure that antibiotics are used appropriately. Effective control measures are however predicated on an understanding of the perceptions and attitudes of the populace towards antibiotics. Many studies around the world have reported the attitudes of persons towards antibiotics citing age, gender and level of education as major predictors of inappropriate antibiotic use [4-8]. A recent study reported poor knowledge in as high as $62 \%$ of non-medical students in a major Nigerian University [9], similar studies performed in Jordan [10], India [4] and Sri-Lanka [11] also reported subpar levels of knowledge amongst students. Such investigations among tertiary level students are important as this population constitutes a segment of the society that is highly educated and more inclined to information about health. The objective of this study was to investigate the level of knowledge, attitudes, and behaviors regarding antibiotics use among the students of a University in Nigeria. 


\section{METHODS}

A cross-sectional study was conducted from January to March 2016 among undergraduate students attending Covenant University, Ogun State. Covenant University has an undergraduate student population of 6000 and is made of four colleges namely, College of Science and Technology (CST), College of Engineering (CoE), College of Business Studies (CBS) and College of Development Studies. Random convenient samples of 357 students were included in this study based on their willingness to complete the self-administered questionnaire.

Students were split into Science and nonscience categories based on the college to which they belong. Students from CST and CoE were categorized as 'Science' students while students from CBS and CDS were categorized as 'Non-science'.

A 35-item questionnaire was developed from existing studies $[5,9,10,12,13]$. The selfadministered questionnaire had three sections; the first section sought to obtain demographic information of participants, the second section assessed patterns of antibiotic usage of students while the third section assessed their perceptions and knowledge of antibiotics.

A subset of 10 questions were used to assess how knowledgeable the respondents were about the subject matter. One point was assigned to correct responses and zero to incorrect responses. Respondents scoring 6 points and above were considered to have good knowledge while respondents scoring below 6 points were considered to have poor knowledge $[4,9,14]$.

All statistical analysis was performed using SPSS software Version 20.0 (SPSS Inc., Chicago, IL, USA). Chi-square test was used to assess relationships between dependent and independent variables to establish statistical significance. A P value of $<0.05$ was considered as statistically significant.

\section{RESULTS}

A total of 357 students were included in this study of which 152 (42.6\%) were male and 203 $(59.6 \%)$ were female. Most respondents were within the age group of $19-21$ (51.5\%). Sixty-six percent of the students included in this study have a background in science while $34 \%$ were from non-science backgrounds (Table 1).

More than half $(60.6 \%)$ of the students had used an antibiotic in the past six months of conducting this study with two thirds $(75.2 \%)$ following the dosage instructions strictly and males having a higher tendency than females to have taken antibiotics (Table 2). Doctors (53.1\%) and Parents/Guardians (22.9\%) prescribed of antibiotics the most while ampicillin (20.7\%) and Penicillin (17.1\%) were the highest prescribed antibiotics (Figs 1 \& 2). In almost half (47.4\%) of the cases where a Doctor prescribed an antibiotic, there was no laboratory test performed. Almost all students (97.9\%) had used an antibiotic without a doctor's prescription with $64.7 \%$ stating that perform self-medication often (Table 3). Pharmacies (39.7\%) and drugs available at home (30.4\%) were the highest sources of antibiotics (Fig 3).

The knowledge assessment showed fair knowledge of antibiotics use and resistance with only $51.7 \%$ of students passing our set threshold for knowledge about antibiotics. Students in the sciences $(54.5 \%)$ had a better knowledge than their non-science $(46.3 \%)$ counterparts with students in CST $(56.0 \%)$ having the highest knowledge scores. Across the different levels of education, first year students had significantly higher knowledge than other levels. Also, knowledge increased with increasing age while more females $(53.7 \%)$ than males $(49.3 \%)$ had good knowledge of antibiotics (Table 4).

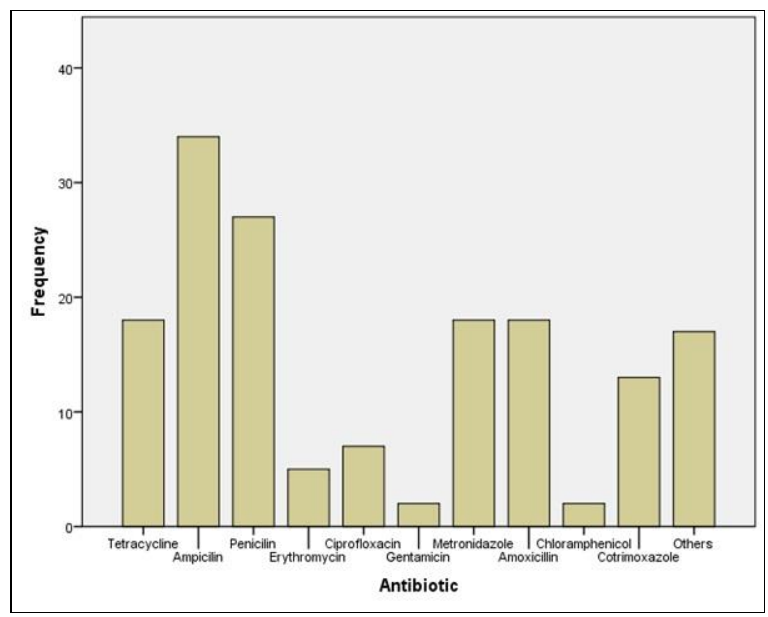

Figure 1. Frequency of drug prescriptions. 
Table 1. Summary of study participants.

\begin{tabular}{lcc}
\hline Sex & Male & $152(42.6 \%)$ \\
& Female & $203(56.9 \%)$ \\
& No Response & $2(0.6 \%)$ \\
\hline Age Group & $14-18$ & $138(38.7 \%)$ \\
& $19-21$ & $184(51.5 \%)$ \\
& $22-24$ & $32(9.0 \%)$ \\
Discipline & No Response & $3(0.8 \%)$ \\
& Science & $235(66 \%)$ \\
\hline College & Non-Science & $121(34 \%)$ \\
& CST & $184(51.5 \%)$ \\
& CoE & $51(14.3 \%)$ \\
& CBS & $82(23.0 \%)$ \\
\hline Level & CDS & $39(10.9 \%)$ \\
& No Response & $1(0.3 \%)$ \\
& 100 & $61(17.1 \%)$ \\
& 200 & $111(31.1 \%)$ \\
& 300 & $32(9 \%)$ \\
\end{tabular}

Table 2. Patterns of antibiotic usage.

\begin{tabular}{|c|c|c|c|c|c|c|}
\hline \multirow[b]{2}{*}{ Questions } & \multicolumn{3}{|c|}{ Yes } & \multicolumn{3}{|c|}{ No } \\
\hline & Male & Female & Total & Male & Female & Total \\
\hline $\begin{array}{l}\text { Have you taken Antibiotics in the past six (6) } \\
\text { months? }\end{array}$ & 95 (62.9) & $\begin{array}{c}119 \\
(58.9)\end{array}$ & $214(60.6)$ & $\begin{array}{c}56 \\
(37.1)\end{array}$ & $83(41.1)$ & $\begin{array}{c}139 \\
(39.4)\end{array}$ \\
\hline $\begin{array}{l}\text { Do You Adhere Strictly to the dosage } \\
\text { instructions }\end{array}$ & $75(75.8)$ & $\begin{array}{c}101 \\
(74.8)\end{array}$ & $176(75.2)$ & $\begin{array}{c}24 \\
(24.2)\end{array}$ & $34(25.2)$ & $58(24.8)$ \\
\hline $\begin{array}{l}\text { Do you think it's important to complete the } \\
\text { drug dosage, even if all symptoms are gone }\end{array}$ & $94(71.2)$ & $\begin{array}{c}131 \\
(74.9)\end{array}$ & 225 (73.3) & $\begin{array}{c}38 \\
(28.8)\end{array}$ & $44(25.1)$ & $82(26.7)$ \\
\hline $\begin{array}{l}\text { Do you always complete your dose as } \\
\text { prescribed by the physician }\end{array}$ & $52(36.9)$ & $85(45.9)$ & $137(42.0)$ & $\begin{array}{c}89 \\
(63.1)\end{array}$ & $\begin{array}{c}100 \\
(54.1)\end{array}$ & $\begin{array}{r}189 \\
(58.0)\end{array}$ \\
\hline Do you keep leftover drugs for future use? & $78(53.8)$ & $\begin{array}{c}111 \\
(59.7)\end{array}$ & $189(57.1)$ & $\begin{array}{c}67 \\
(46.2)\end{array}$ & $75(40.3)$ & $\begin{array}{c}142 \\
(42.9)\end{array}$ \\
\hline $\begin{array}{l}\text { Are you aware that improper use of antibiotics } \\
\text { could be harmful? }\end{array}$ & $\begin{array}{c}106 \\
(74.6)\end{array}$ & $\begin{array}{c}146 \\
(75.3)\end{array}$ & $252(75.0)$ & $\begin{array}{c}36 \\
(25.4)\end{array}$ & $48(24.7)$ & $84(25.0)$ \\
\hline Do you take Antibiotics for Cold? & $45(34.9)$ & $62(36.3)$ & $107(35.7)$ & $\begin{array}{c}84 \\
(65.1)\end{array}$ & $\begin{array}{c}109 \\
(63.7)\end{array}$ & $\begin{array}{c}193 \\
(64.3)\end{array}$ \\
\hline If yes, do you get better after taking antibiotics & $57(41.9)$ & $79(58.1)$ & $136(85.5)$ & $\begin{array}{c}15 \\
(65.2)\end{array}$ & $8(34.8)$ & $23(14.5)$ \\
\hline
\end{tabular}

Table 3. Patterns of antibiotic usage.

\begin{tabular}{lccccccccccc}
\hline Question & \multicolumn{3}{c}{ Always/Often } & \multicolumn{3}{c}{ Rarely/Sometimes } & \multicolumn{3}{c}{ Never } \\
& Male & Female & Total & Male & Female & Total & Male & Female & Total \\
& & & & & & & & & \\
Have you ever used antibiotics & 95 & 123 & 218 & 46 & 66 & 112 & 1 & $6(3.1)$ & 7 \\
without a doctor's prescription? & $(66.6)$ & $(63.1)$ & $(64.7)$ & $(32.4)$ & $(33.8)$ & $(33.2)$ & $(0.7)$ & $(2.1)$ \\
If the doctors refused to prescribe & 29 & 34 & 63 & 105 & 145 & 250 & 13 & 14 & 27 \\
$\begin{array}{l}\text { antibiotics for you, would you insist } \\
\text { on the doctor doing so? }\end{array}$ & $(19.7)$ & $(17.6)$ & $(18.5)$ & $(71.4)$ & $(75.1)$ & $(73.5)$ & $(8.8)$ & $(7.3)$ & $(7.9)$
\end{tabular}


Table 4. Antibiotic knowledge assessment.

\begin{tabular}{|c|c|c|c|c|}
\hline Variables & & Poor Knowledge & Good Knowledge & $P$ value \\
\hline \multirow[t]{2}{*}{ Discipline } & Science & $107(45.5)$ & $128(54.5)$ & 0.143 \\
\hline & Non-Science & $65(53.7)$ & $56(46.3)$ & \\
\hline \multirow[t]{4}{*}{ College } & CST & $81(44.0)$ & $103(56.0)$ & 0.314 \\
\hline & CoE & $26(51.0)$ & $25(49.0)$ & \\
\hline & CBS & $42(51.2)$ & $40(48.8)$ & \\
\hline & CDS & $23(59.0)$ & $16(41.0)$ & \\
\hline \multirow[t]{5}{*}{ Level } & 100 & $22(36.1)$ & 39 (63.9) & 0.004 \\
\hline & 200 & $69(62.2)$ & $42(37.8)$ & \\
\hline & 300 & $14(43.8)$ & $18(56.2)$ & \\
\hline & 400 & $46(40.4)$ & $68(59.6)$ & \\
\hline & 500 & $18(51.4)$ & $17(48.6)$ & \\
\hline \multirow[t]{3}{*}{ Age Group } & $14-18$ & $69(50.0)$ & $69(50.0)$ & 0.439 \\
\hline & $19-21$ & $89(48.4)$ & $95(51.6)$ & \\
\hline & $22-24$ & $12(37.5)$ & $20(62.5)$ & \\
\hline \multirow[t]{2}{*}{ Sex } & Male & $77(50.7)$ & $75(49.3)$ & 0.417 \\
\hline & Female & 94 (46.3) & 109 (53.7) & \\
\hline
\end{tabular}

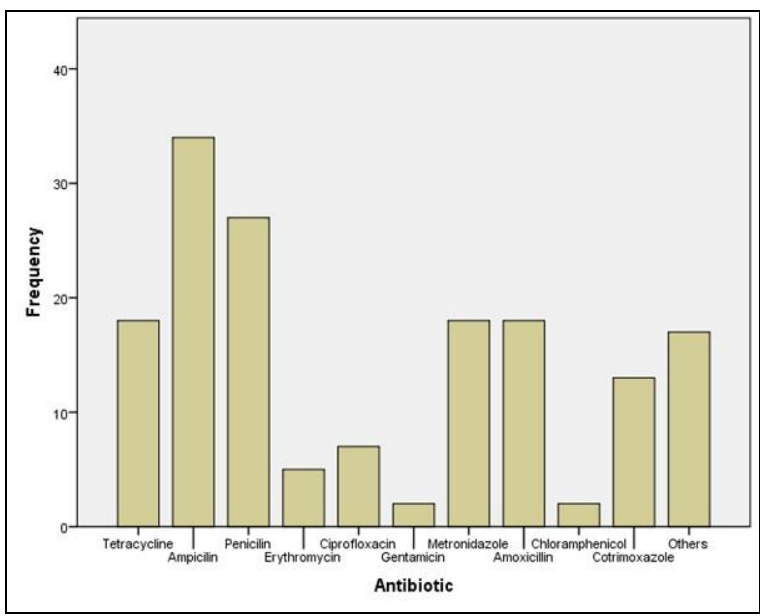

Figure 2. Types of antibiotics used.

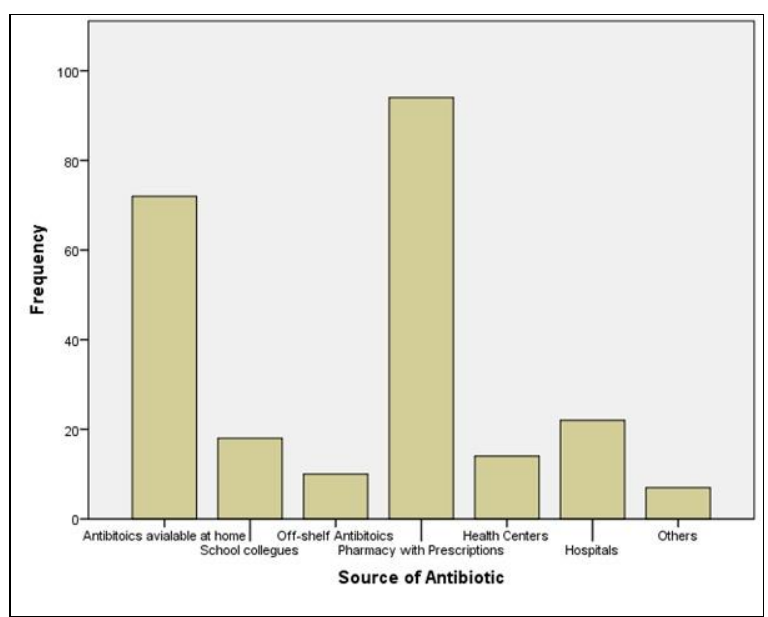

Figure 3. Sources of antibiotics.

\section{DISCUSSION}

Antibiotic resistance remains a significant public health problem worldwide. There is a paucity of information on the knowledge of antibiotic use among Nigerian university students. This study assessed the knowledge, attitude and practice of antibiotic usage and resistance among students in a Nigerian University.

Results from this study showed average knowledge (Mean Score: $5.51 \pm 2.69$, Range 010) of antibiotic usage with more than half of students surpassing the knowledge threshold in the assessment. Only $35.7 \%$ of students stated that they take antibiotics for cold, adding more credence to the good level of antibiotic awareness of the students. Level of study was a major predictor for good knowledge $(P=0.004)$ supporting the findings of an earlier study [9]. Findings from this study however don't mirror a similar study where age was found to be a predictor of knowledge [9], this may be due to the small age range (14-24) of participants in this study. More than half of the students agreed that antibiotic misuse was a major driver of antibiotic resistance and that antibiotic resistance is a problem in Nigeria, however almost all $(98.5 \%)$ of the students had used an antibiotic in the past without prescription. This is indicative of an unwillingness to adhere to what they know to be the right thing to do. This study 
also shows some evidence of patient pressure on doctors to prescribe antibiotics even when it is unrequired; we suspect this may be a driver of illicit antibiotic.

The highest knowledge scores $(6.48 \pm 2.31 \mathrm{Cl}$ 5.88-7.07) were however found amongst first year students, this is in disagreement with several studies that found higher level students to have more knowledge [4,9]. About $60.6 \%$ of the participants had taken antibiotics in the 6 months preceding the study of which two-thirds stated that they seldom complete the antibiotic dosage. The proportion of students who obtained their antibiotics from either a doctor or pharmacist is similar $(64.2 \%)$ to previous studies $[10,15]$. Parents however were responsible for almost a quarter of all prescriptions. Ampicillin $(20.7 \%)$ and Penicillin (17.1\%) were the most used antibiotics. Major sources of antibiotics were the pharmacy (39.7\%) and left-over antibiotics available at home (30.4\%). The high use rates of Ampicillin and Penicillin in this study signals an over dependence on these antibiotics and poses a major threat to public health in Nigeria has there have been reports of high levels of resistance to said drugs $[16,17]$. Furthermore, the fact that most students (67.4\%) answered that antibiotics could treat viral infections is a cause for concern and indicative of antibiotic overuse. This poses a major threat to public health as the aforementioned antibiotics form the main stay of treatment in many resource poor regions.

\section{Conclusion}

It is evident from this study that while students have good knowledge of antibiotics and antibiotic resistance, their attitudes to antibiotics is not in tandem with their knowledge. It is therefore imperative to reorient students via sensitisation campaigns in a bid to reducing the occurrence of antibiotic misuse and subsequently antibiotic resistance.

\section{ACKNOWLEDGMENTS}

Declaration of Conflicting Interests: The authors declare no conflicts of interest

Acknowledgment: The authors would like to thank all the students who participated in this study
Ethical Statement: This study was reviewed and approved by the Biological Sciences Ethical Review Committee, Covenant University with approval

number:

\section{CU/BIOSCRECU/BIO/2016/034}

\section{REFERENCES}

1. Renaud J, Antunovic M, Suljagic V. The Analysis of antibiotic consumption within the tertiary healthcare institution in Serbia during 10-year period (2001-2010). Int J Pharm Pharmaceutic Sci 2016; 8: 401-403.

2. Mgearchbahurike A, Idowu I, Igwilo C. Antibiotic Utilization and Prescribing Patterns in a Nigerian University Medical Center. Nigerian J Pharm Res 2010; 8 .

3. Morgan DJ, Laxminarayan R, Morgan DJ, et al. Non-prescription antimicrobial use worldwide: a systematic review. The Lancet Infectious Diseases 2011; 11:692-701.

4. Ahmad A, Khan MU, Moorthy J, Jamshed SQ, Patel I. Comparison of knowledge and attitudes about antibiotics and resistance, and antibiotics self practicing between Bachelor of Pharmacy and Doctor of Pharmacy students in Southern India. Pharmacy Practice 2015; 13:1-7.

5. Tagoe D, Attah C. A Study of Antibiotic Use and Abuse in Ghana: a case study of the Cape Coast Metropolis. The Internet Journal of Health 2010; 11:1-6.

6. Zhu X, Pan H, Yang Z, Cui B, Zhang D, Ba-Thein W. Self-medication practices with antibiotics among Chinese university students. Public Health 2016; 130: 78-83.

7. Jamhour A, El-Kheir A, Salameh $P$, Hanna PA, Mansour $\mathrm{H}$, Mansour $\mathrm{H}$. Antibiotic knowledge and self-medication practices in a developing country: A cross-sectional study. Am J Infect Control 2017; 45:384-388.

8. Aldhafar AS, Talat W. Knowledge, Attitude, and Practice toward the Usage of Antibiotics among Public in Al-Ahsa, Saudi Arabia. International J Sci Study 2017; 4:14-17.

9. Asogwa I, Offor S, Mbagwu H. Knowledge, Attitude and Practice towards Antibiotics Use among Non-medical University Students in Uyo, Nigeria. Journal of Advances in Med Pharma Sci 2017;15:1-11.

10. Abu-helalah M, Alshraideh $\mathrm{H}$, Hijazeen J, Al-zu A. Antibiotics Use and Misuse among University Students in Jordan. Bulletin of Environment, Pharmacology and Life Sciences 2015; 4:62-71.

11. Zawahir S, Hettiarachchi C, Morrissey H. Assessing Knowledge, Perception And Attitudes About Antibiotics Among Final Year Pharmacy 
Undergraduates In Sri Lanka. Int J Pharm and Pharmaceutical Sci 2017; 9:234.

12. Rathish D, Wijerathne B, Bandara S, et al. Pharmacology education and antibiotic selfmedication among medical students: a crosssectional study. BMC Research Notes 2017;10:337.

13. Mukharjee SK, Mahmud I, Akter S, Hossain S. Knowledge, attitudes and practices regarding antibiotic use among the students of microbiology department at noakhali science and technology. Journal of Drug Delivery \& Therapeutics 2017; 7:3437.

14. Inácio $\mathrm{J}$, Barnes L-M, Jeffs $\mathrm{S}$, et al. Master of Pharmacy students' knowledge and awareness of antibiotic use, resistance and stewardship. Currents in Pharmacy Teaching and Learning 2017; 9:551559.

15. Sanya T, Titilayo O, Adisa R, Segun J. Use of antibiotics among non-medical students in a Nigerian university. African Health Sciences 2014; 13: 1149 .

16. Udobi CE, Obajuluwa AF, Onaolapo JA. Prevalence and Antibiotic Resistance Pattern of Methicillin-Resistant Staphylococcus aureus from an Orthopaedic Hospital in Nigeria. BioMed Research Int 2013; 2013:1-.

17. Sani RA, Garba SA, Oyewole OA. Antibiotic Resistance Profile of Gram Negative Bacteria Isolated from Surgical Wounds in Minna, Bida, Kontagora and Suleja Areas of Niger State. Am J Med Med Sci 2012; 2:20-24. 